\title{
Integrating Geological Information and Electrical Resistivity Tomography for Mapping the Main Groundwater Bearing Layers in Ancient Babylon City, Iraq
}

\author{
Mohammed M. Al-Hameedawi ${ }^{1,2, *}$, Jassim M. Thabit ${ }^{2}$ and Firas H. Al-Menshed $^{1}$ \\ The General Commission for Groundwater, Ministry of Water Resources, Baghdad, Iraq \\ Department of Geology, College of Science, Baghdad University, Baghdad, Iraq \\ Correspondence: mohammedmohsenali@yahoo.com
}

\begin{abstract}
Received:
12 September 2021

Accepted:

2 November 2021

Published:

31 January 2022

Electrical resistivity tomography was conducted in nine locations within ancient Babylon city, using Wenner-Schlumberger array, to map groundwater-bearing layers. The inverted models were integrated and correlated with the geological information extracted from six boreholes drilled during the 1970s. The interpreted inverse models of the Wenner-Schlumberger show identical corresponding with the lithological sequence of the boreholes. This corresponds related to the presence of one thick layer of sand deposits, with a thickness that may reach $60 \mathrm{~m}$, and several thin interbedded clay layers that are locally extended. The sand layer is considered the main groundwater-bearing layer in the area. Further, the results proposed that a high discharge rate from any future boreholes which will be drilled for lowering the groundwater levels in the ancient Babylon area can easily cause a washing out of sand deposits which in turn can cause serious damages in archaeological remaining even after all measures to prevent sand washing.
\end{abstract}

\section{Abstract}

Keywords: Electrical resistivity tomography; Ancient Babylon city; Boreholes; Lowering groundwater levels.

\section{Introduction}

The ancient Babylon city lies within the Mesopotamia zone of the stable shelf as Jassim and Goff (2006) divisions. It is located about $90 \mathrm{~km}$ south of the capital Baghdad and $10 \mathrm{~km}$ north of AL-Hilla city. It is occupied an area of about $9.5 \mathrm{~km}^{2}$ and is divided by the Shatt AL-Hilla river, a Euphrates river branch (Fig. 1). Two artificial lakes connected by a circumferential canal intermediate the study area. Furthermore, the Babylon city canal passed the study area on the northern side. The major problem in ancient Babylon city is the shallow groundwater level, which is $0.5 \mathrm{~m}$ to $4 \mathrm{~m}$ in the center of ancient Babylon (Al-Sam et al., 1979). It leads to being a problem rather than a water resource that restricted the archeological investigations and surveys. Undiscovered archeological structures beneath the surface are already embedded within shallow groundwater. The study area is characterized by existing of Shatt AL-Hilla, Babil river, and the artificial (or Babylon) canal and its connected lakes. Shat AL-Hilla river and Babil river have the major effect on the hydrogeological sitting in the study area. They are considered the main source of groundwater recharge (Al-Sam et al., 1979). Geologically, quaternary sediments of the floodplain and Aeolian sediments cover the study area. The core drilling boreholes 
present that the upper $10 \mathrm{~m}$ comprise a large number of bricks and silty clay, especially in the central part of the city. From 10 to $28 \mathrm{~m}$, the fine sand is considered as the first groundwater-bearing layer (unconfined aquifer). From 28 to $30 \mathrm{~m}$, brown clay acts as an impermeable or semi-impermeable layer. From 30-45m, medium sand can be considered as a second bearing layer (confined aquifer) or as a part of the first aquifer (AL-Sam et al., 1979). Few geophysical and hydrogeological studies on ancient Babylon city are available. Some of them discuss the hydrogeological setting of the city in detail, such as Al-Sam et al. (1979), others deal with small locations or with specific subjects within the city, such as Nehaba et al. (2019). Al-Sam et al. (1979) conducted a preliminary study on the possibility of lowering groundwater levels in ancient Babylon city. The results revealed to draw a map showing the level of the groundwater and its direction in Babylon city. They concluded that the Shatt AL-Hilla river took part by raising the groundwater level by about 4-5 m. Karim (2005) simulated a numerical model for dewatering the groundwater level in the ancient Babylon city based on re-analysis pumping test data gathered by the Al-Furat Center of Studies and Design of Irrigation Projects (FCSDIP) in 1989. The model was built based on drilling 45 boreholes in an area of $5.5 \mathrm{~km}^{2}$. Each borehole is assumed to penetrate a depth of 45 $\mathrm{m}$ with a discharge rate of $17 \mathrm{l} / \mathrm{s}$. The results revealed possibly lowering the groundwater level to the required depth in 250 days. CEB, (2012) developed a conceptual model of how surface water and groundwater flow through the ancient city. They used the same data of FCSDIP. The model results confirmed the output of Karim, (2005) but with doubt about the ability of drilling 45 boreholes on the site.

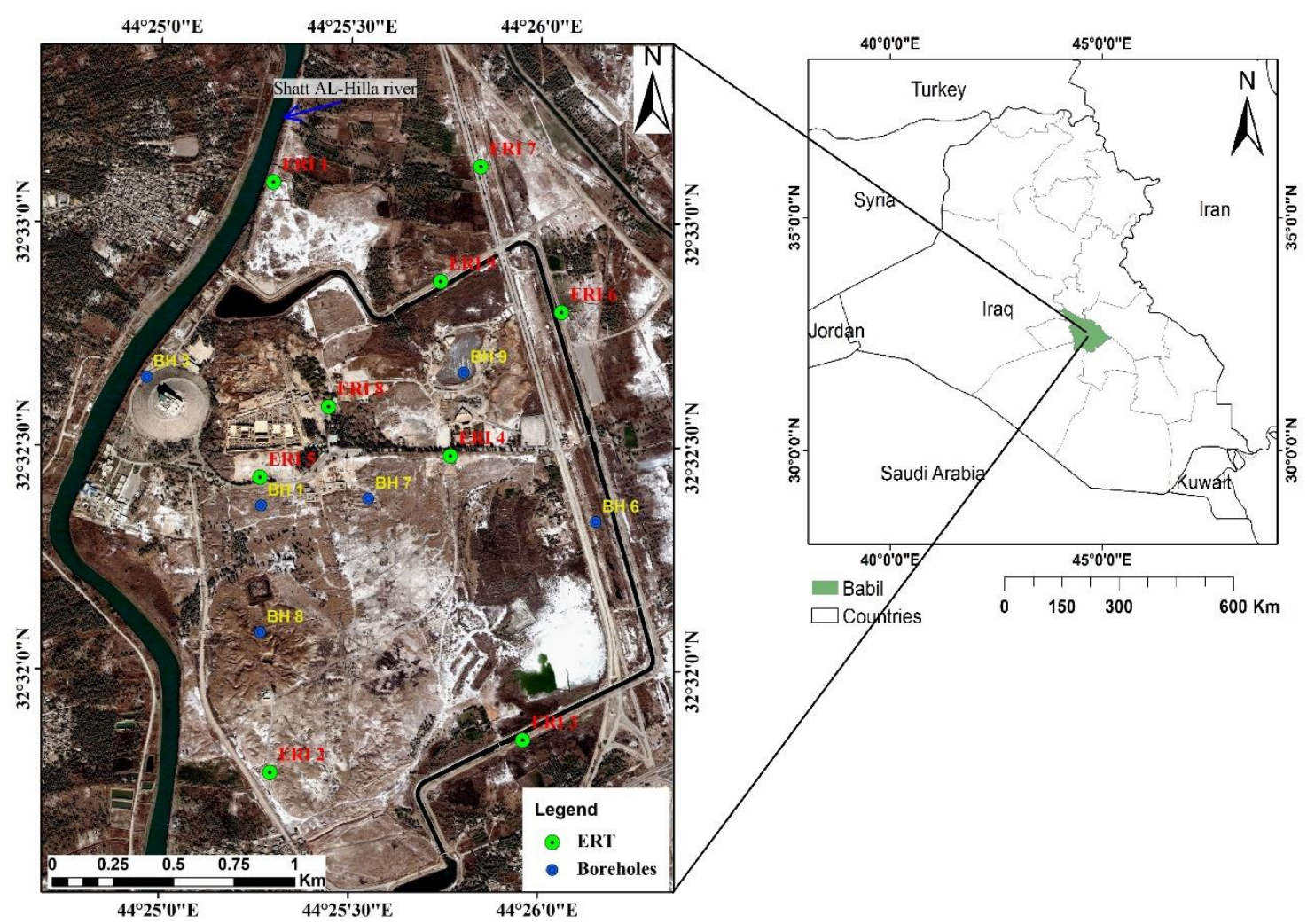

Fig. 1. Ancient Babylon city, Both the boreholes and the Electrical Resistivity Topography station are distributed along the area

The geophysical studies in the ancient city were restricted to very small areas, and most of them applied for archaeological purposes. However, Hannina (2013) attempted to apply Vertical electrical sounding (VES) to determine the groundwater level in the central and eastern parts of ancient Babylon 
city. The VES data showed high distortion. Based on these VES data, the water level is suggested to be $8 \mathrm{~m}$. The present study will be attempted to determine the groundwater-bearing layers (aquifers) in ancient Babylon city. This will be normally done by applying two-dimension (2D) of electrical resistivity tomography (ERT) using Wenner-Schlumberger array and then correlated the obtained results from ERT inverse models with the available geological information from boreholes drilled by Al-Sam et al. (1979). The object is trying to answer the following two questions. Are there two separated groundwater-bearing layers in the study area? How far the suggested models for lowering groundwater will succeed according to the results of this study.

\section{Materials, Methods, and Fieldwork}

The 2D ERT has been developed during the last three decades for the exploration of complex geology, especially when the conventional VES or other techniques become unsuitable (Griffiths and Barker, 1993). It has been progressively used in shallow prospecting and intermediate depths for different aspects, including environmental, hydrogeology, engineering, archaeology, and mining (Dahlin, 1996; Thabit and Al-Hameedawie, 2014; Al-Zubedi and Thabit, 2015; Amini and Ramazi, 2016; Al-Menshed and Thabit, 2017; Fernández-Álvarez et al., 2017). The conventional VES method does not consider the lateral changes in the subsurface materials, while the ERT allows both lateral and vertical changes in the subsurface to be imaged accurately. It is fully controlled by advanced multi-channel resistivity meters. Wenner-Schlumberger array (Fig. 2) is frequently used for different investigations, including hydrogeology (Al-Hameedawi and Thabit, 2017). Initially, this array consists of four electrodes. Two for current electrodes, called (C1-C2), where the electrical current can be injected into the subsurface by them. The potential difference will be measured by the other two electrodes, which are called potential electrodes (P1-P2). The potential electrodes always occur between the current electrodes where the distance between the potential electrodes (P1-P2) is called a-spacing (a), while the ratio distance between $\mathrm{C} 1$ and $\mathrm{P} 1$ or $\mathrm{C} 2$ to $\mathrm{P} 2$ to the distance between the (P1-P2) is called n-factor (Fig. 2) (Loke, 2020).

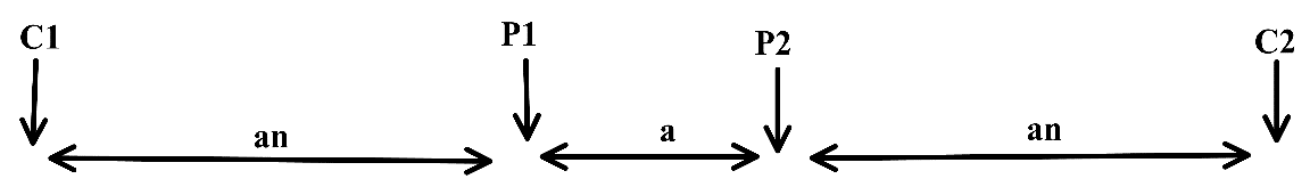

Fig. 2. Wenner-Schlumberger array

The fieldwork is done in December 2019 using the SYSCAL Pro switch 120 electrodes resistivity meter from Iris. Nine 2DERT stations, labeled ERT1-ERT9, were collected along the study area (Fig. 1). The length of these stations varies between $895 \mathrm{~m}$ (180 electrodes) at station ERT6 using roll along technique and $270 \mathrm{~m}$ (56 electrodes) at station ERT5. The initial a-spacing is set to be $5 \mathrm{~m}$ while the $\mathrm{n}$-factor is set to be 6 a because, beyond this value, the signal-to-noise ratio will be dramatically reduced and this array will tend to pick more noisy data (Loke, 2020). Before data acquisition, each electrode is firmly planted in the ground to reduce the bad contact between electrodes and the ground. Further, the ground resistance (RS) test is applied to all electrodes. Abnormal high RS values mean that there is a bad contact between the electrode and the ground. The RS values for all stations were normal and ranged from 0.1 to 0.5 Khom only. Six boreholes drilled by Al-Sam et al. (1979) were considered for this study. The lithology of these boreholes shows an interbedded sequence between thick sand (fine and medium) and thin silty clay layers (Fig. 3). At the top, a relatively thick layer (about $10 \mathrm{~m}$ on average) of silty clay is present. 


\section{Results}

All the ERT stations are processed using Res2Dinv software from Geotomo software where the same parameters, like damping factor and flatness filter, are applied to all the measured data. The inversion process is performed using the smoothness-constrained least-square optimization (or L2 norm) method, which is optimal for subsurface consists of regions that gradually change with depth (Loke et al., 2003).

$\mathrm{BH} 1$

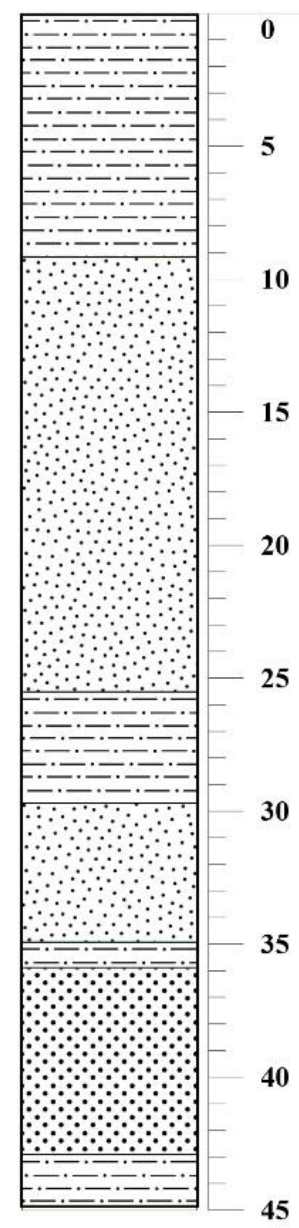

$\mathrm{BH} 3$

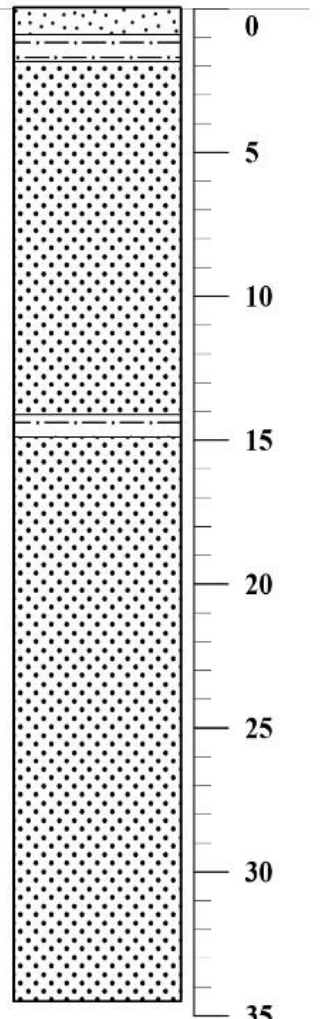

35
BH6

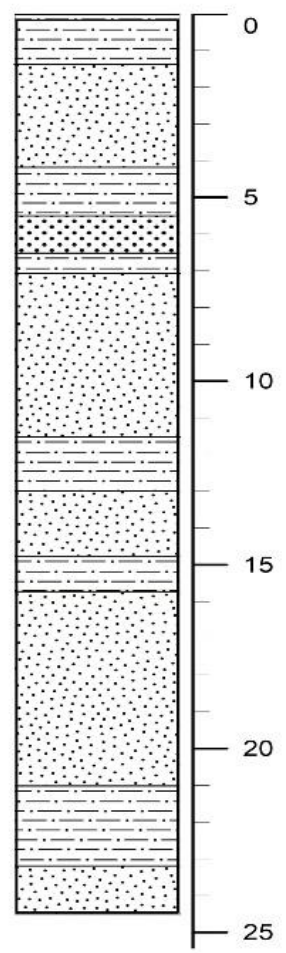

Fig. 3. The lithological sequence of three selected boreholes with the study area, modified after Al-Sam et al., 1979

The resultant inverse models of the ERT stations show an optimal corresponding with the lithology sequence of the boreholes in the study area. Fig. 4 shows an inverse model of the ERT5 with the nearest borehole (BH1). It can be seen that both are identical. Here, the layer of the silt clay deposits near the surface is corresponding to low resistivity values horizon on the ERT5 inverse model, which is mainly less than $9 \Omega \mathrm{m}$. The thick sand layer agrees to the higher resistivity values horizon that ranged between $9 \Omega \mathrm{m}$ to over $50 \Omega \mathrm{m}$. The thin interbedded layers of the silty clay deposits in the BH1 do not appear on the ERT5 inverse model. This may occur because the sensitivity the resistivity method is decreasing with depth. As a result, thin layers may not recognize. To overcome this issue, dense data measurements should be collected. 


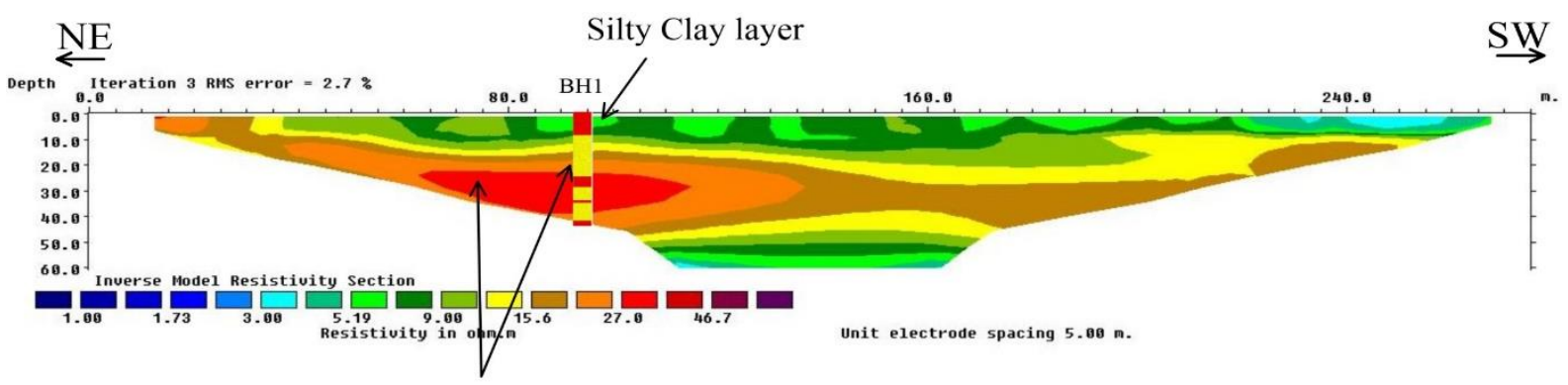

Sand layer (groundwater-bearing layer)

Fig. 4. ERT5 inverse model and the nearest borehole (BH1)

In this section, we will discuss only three ERT inverse models (ERT1, ERT4, and ERT6) as all the inverse models showed approximately the same horizons sequence. The inverse model of the ERT1 reveals the presence of a thick high resistivity horizon (Fig. 5a). As the location of the ERT1 station occurs near the Shat AL-Hila river, this thick horizon represents the sand layer which is also corresponding to the lithology sequence of the BH3 (Fig. 3, and Fig.1 to compare the locations of the boreholes and the ERT stations). This thick sand layer considers as the main groundwater bearing layer aquifer in this area. The same horizon also appears in the ERT4 and ERT6 inverse models but with lower resistivity values (Fig. 5b, and c). The reason for decreasing the resistivity because of increasing the salinity of the groundwater within the sand layer whenever it becomes far from the river. These ERT inverse models show that the thickness of the sand layer (or groundwater bearing layer) may reach $60 \mathrm{~m}$.

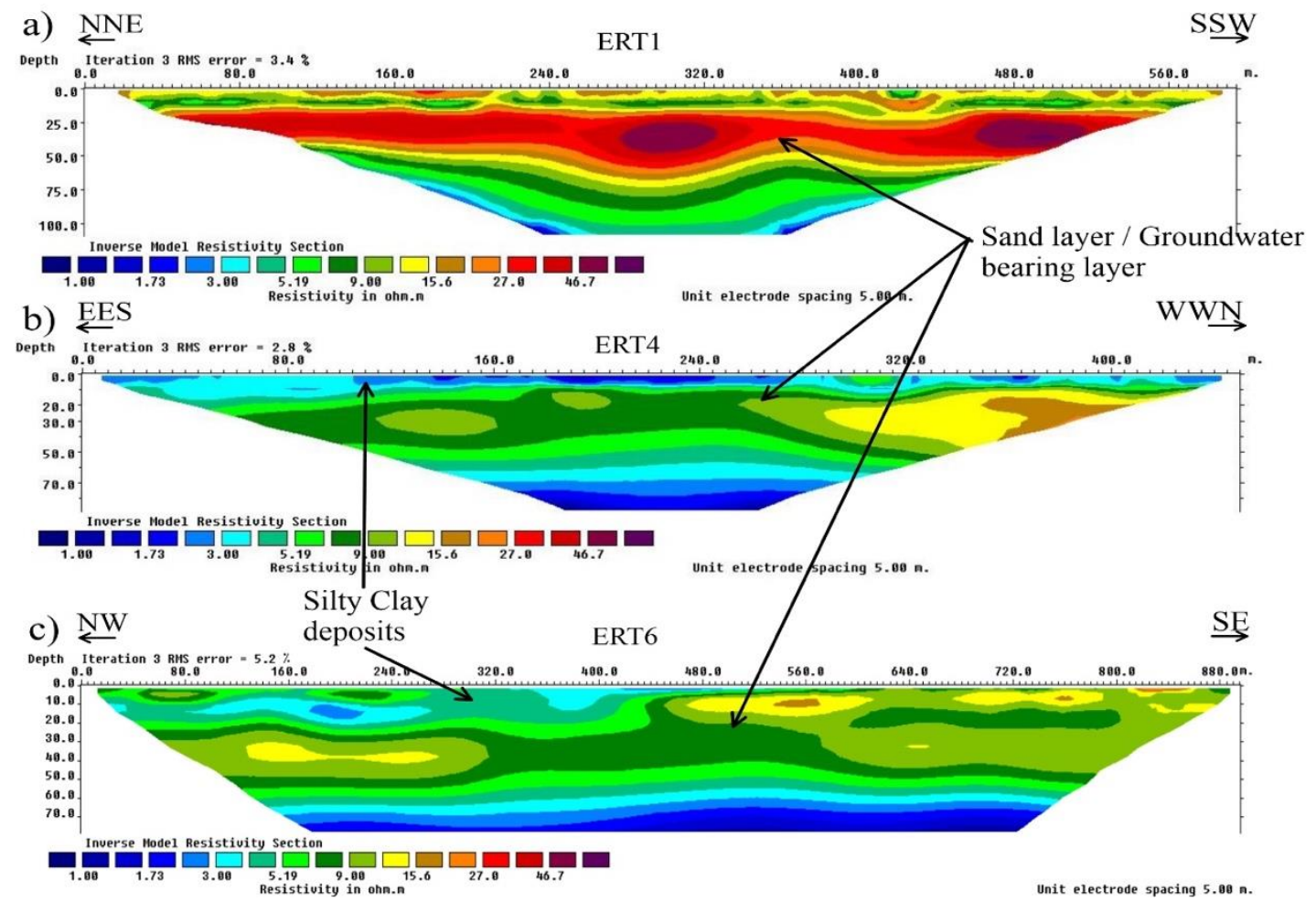

Fig. 5. The inverse models of a) ERT 1; b) ERT4; and c) ERT6

Two cross-sections (Fig. 6) are created in order to integrate the ERT results and the boreholes. Here, we considered the horizons of the ERT inverse model as layers and the successive layers below the midpoint on the inverse models to be measured. The purpose of this integration is trying to gain more 
details about the distribution of the sediments in the study area, especially the groundwater bearing layer. The first cross section passes through ERT1, BH3, ERT5, BH1, BH8, and ERT2 and occurs parallel to the Shatt AL-Hilla river (Fig. 7). It is obvious that the sand layer is dominated in the location of this cross section, while the silty clay deposits are present as thin interbedded layers. The second cross section passes through ERT7, ERT9, BH9, ERT4, BH7, and ERT3 (Fig. 8). It is parallel to the first cross section. In this section, the silty clay layers appear thicker, especially near the surface. Also, a thick silty clay layer is shown between BH7 and ERT3. Based on the above results, it can be concluded that there is one groundwater bearing layer (Sand layer) instead of two layers (Al-Sam et al., 1979)

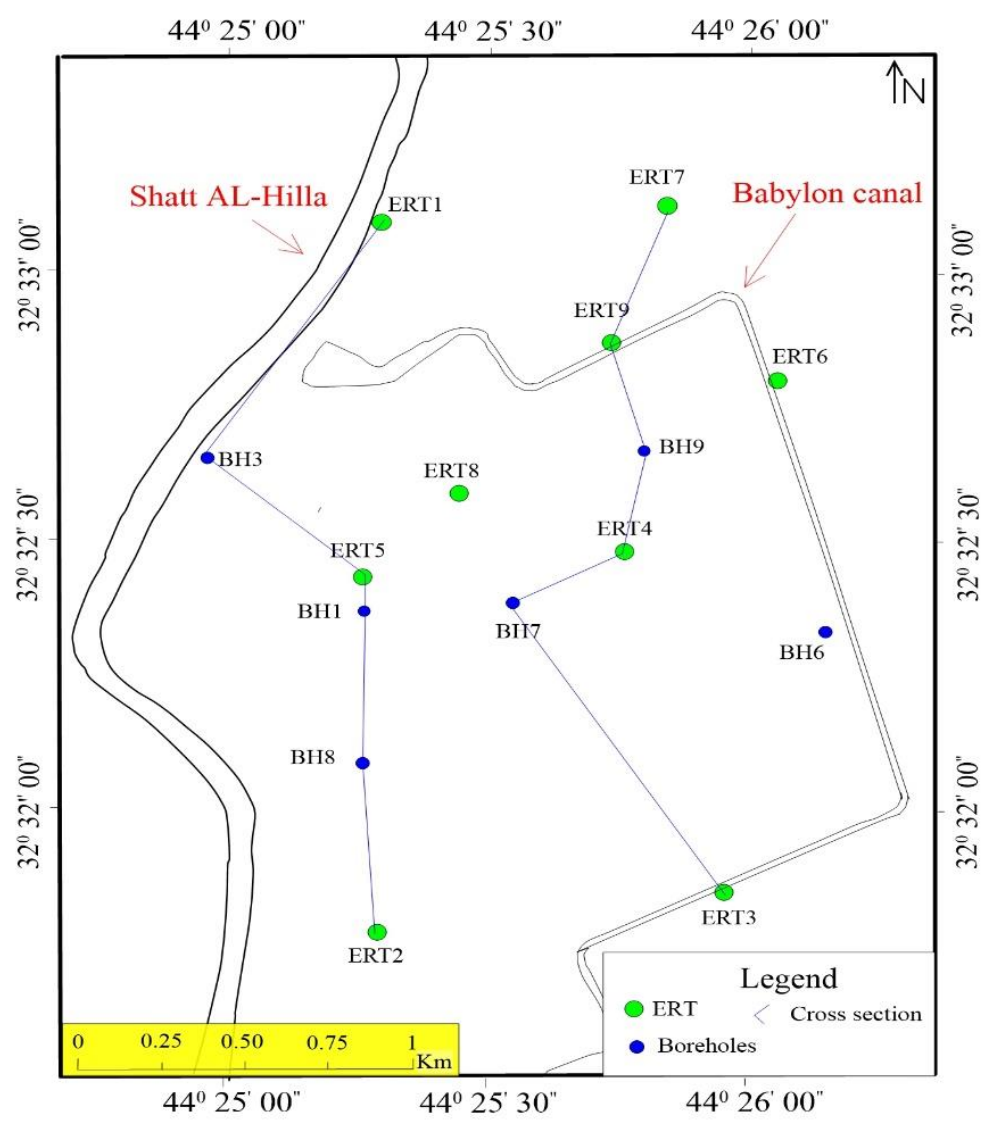

Fig. 6. The location of the cross section in the study area

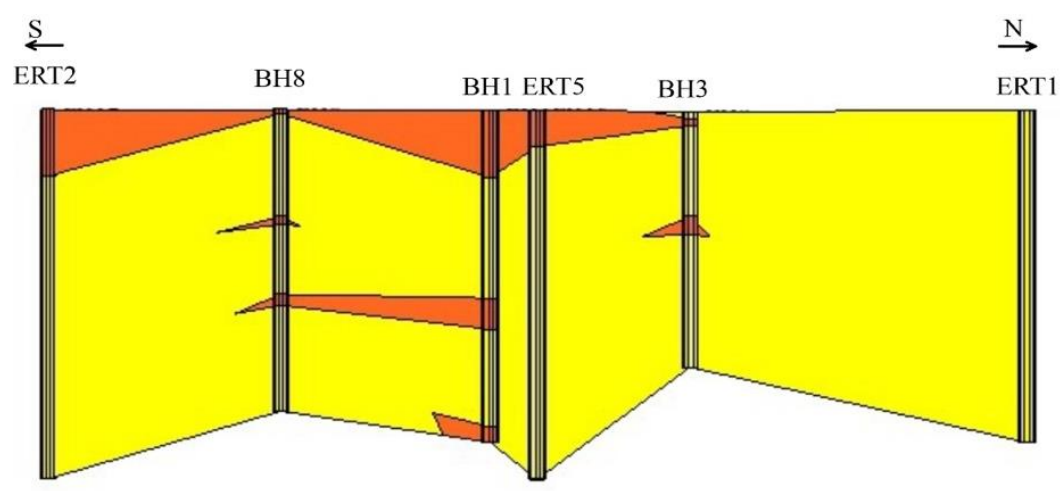

Materials

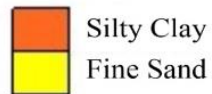

Fig. 7. The first cross section which passes through ERT1, BH3, ERT5, BH1, BH8, and ERT2 


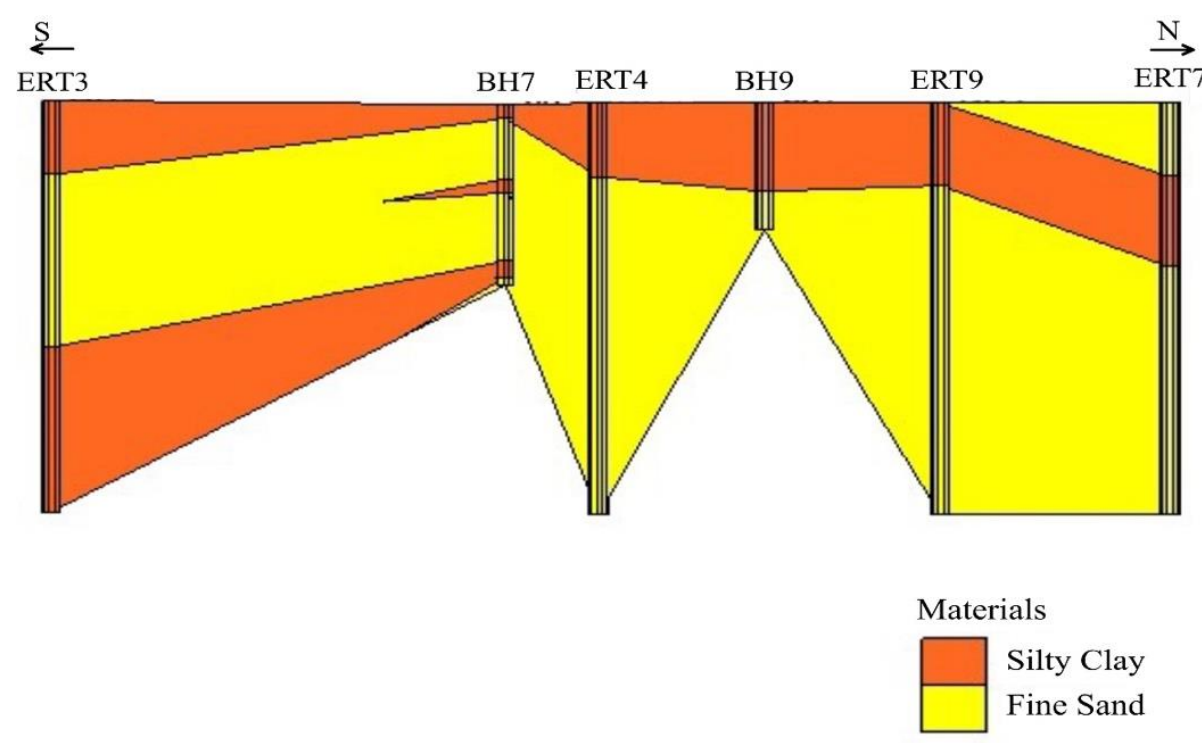

Fig. 8. The second cross section which passes through ERT7, ERT9, BH9, ERT4, BVH7, and ERT3.

\section{Discussion}

Al-Sam et al. (1979) mentioned that there are two groundwater-bearing layers in the study area. The first (upper) layer comprises fine sand of $18 \mathrm{~m}$ of average thickness. The second (lower) layer comprises medium sand with an average thickness of $15 \mathrm{~m}$. Both are separated by a thin impermeable or semi-impermeable clay layer, suggesting that the second layer may be part of the first layer. However, this impermeable clay layer did not appear in all geological formations of the boreholes. Instead, interbedded silty clay thin layers with sand deposits are shown in the lithological sections of these boreholes. These silty clay thin layers are semi-impermeable and have limited extension within the study area. Meaning that there is a hydraulic connection between sand layers, making them one groundwater-bearing layer. Further, the ERT inverse models confirm that there is one layer of sand deposits extended along the entire area with a thickness that may reach $60 \mathrm{~m}$, starting from depth of about $10 \mathrm{~m}$ below the surface. The suggested numerical models by Karim (2005) for lowering groundwater in ancient Babylon city proposed drilling 45 boreholes with a depth of $45 \mathrm{~m}$ and discharge of $17 \mathrm{l} / \mathrm{s}$ for each one. these boreholes are designed to pump the water from a depth between 30 to $45 \mathrm{~m}$, which comprises medium sand. The lithology sequence of the boreholes suggested that the fine and medium sand deposits are arbitrarily distributed in the study area. Therefore, a discharge rate of $17 \mathrm{l} / \mathrm{s}$ can easily cause a washout of sand deposits during this heavy pumping, which in turn can cause serious damages in archaeological remaining even after all the measures to prevent sand washing.

\section{Conclusions}

The main problem in ancient Babylon city is the shallow groundwater levels that cover its archaeological remnants and restricted archaeologists' investigation. Therefore, nine ERT stations are performed in the study area and their inverse models are jointly integrated with the geological information extracted from six boreholes drilled during the 1970s. The resultant inverse models of ERT show an optimal corresponding with the lithological sequence of these boreholes, revealing the existence of a thick sand layer with resistivity range between $9-50 \Omega \mathrm{m}$ and thin silty clay layers with a resistivity less than $9 \Omega \mathrm{m}$. The Wenner-Schlumberger inverse models show that the thickness of the sand layer (or groundwater-bearing layer) may reach $60 \mathrm{~m}$. These results are evaluated and compared with some previous studies which are revealed that the sand layer is dominated while the interbedded clay layers are locally extended in the study area. That's means that there is one thick 
groundwater-bearing layer of sand deposits. Further, the results referred that heavy discharge rate from any future drilling of boreholes for dewatering the groundwater levels can easily cause a washing out of sand deposits, which in turn can cause serious damages in archaeological remaining even after all the measures to prevent sand washing. Discharge not more that $6 \mathrm{l} / \mathrm{s}$ is preferable for a locally drilled borehole around an archaeological site to be excavated in future. This discharge will create a drawdown of about $6 \mathrm{~m}$ near the boreholes.

\section{Acknowledgements}

Our Sincere thanks to the General Commission for Groundwater, Ministry of Water Resources. Iraq. Many thanks to all those who helped us during the field survey in Heritage Babylon City. The authors are very grateful to the reviewers, Editor in Chief Prof. Dr. Salih M. Awadh, the Secretary of Journal Mr. Samir R. Hijab, and the Technical Editors for their great efforts and valuable comments.

\section{References}

Al-Hameedawi, M.M., Thabit, J.M., 2017. Comparison between four electrode arrays in delineating sedimentary layers of alluvial fan deposits in eastern Iraq using a 2D imaging technique. Environmental Earth Science, $76(15), 525$.

Al-Menshed, F. H., \& Thabit, J. M. 2017. Evaluation of 2D resistivity imaging technique for delineating subsurface seepage of hydrocarbon-contaminated water southeast of Karbala city, Iraq. Environmental Science and Pollution Research, 24(7), 6523-6531.

Al-Sam, S., Ibrahim, A., \& Satar, A., 1979. Preliminary study about the possibility of lowering the underground water level in Babylon. Directorate General of Geological Survey, Baghdad. 32p.

Al-Zubedi, A.S., Thabit, J.M., 2015. Use of 2D azimuthal resistivity imaging in delineation of the fracture characteristics in Dammam aquifer within and out of Abu-Jir fault zone, Central Iraq. Arabian Journal of Geoscience, 9 (1).

Amini, A., Ramazi, H., 2016. Application of electrical resistivity imaging for engineering site investigation. A case study on prospective hospital site, Varamin, Iran. Acta Geophysica, 64 (6), 2200-2213.

Consulting engineering bureau, 2012. Hydrological study of ancient Babylon site. University of Baghdad, College of Engineering, 62p

Dahlin, T., 1996. 2D resistivity surveying for environmental and engineering applications. First Break, 14 (7), 275-283.

Fernández-Álvarez, J. P., Rubio-Melendi, D., Castillo, J.A.Q., González-Quirós, A., Cimadevilla-Fuente, D., 2017. Combined GPR and ERT exploratory geophysical survey of the medieval Village of Pancorbo Castle (Burgos, Spain). Journal Applied Geophysics, 144, 86-93.

Hannina, S., E., 2013. Geophysical Exploration Studies for Babylon Archaeological City. Unpublished, Ph.D. thesis. University of Baghdad, college of science. 162p

Jassim, S. Z., \& Goff, J. C., 2006. Geology of Iraq. DOLIN, Geological Society of London. 337pp.

Karim, I. B., 2005. Lowering of groundwater levels in the Ancient City of Babylon. Unpublished, Ph.D. Thesis. University of Technology, 91pp.

Loke, M. H., 2020. Tutorial: 2-D and 3-D electrical imaging surveys. Geotomo software. 231p.

Loke, M. H., Acworth, I., \& Dahlin, T., 2003. A comparison of smooth and blocky inversion methods in 2D electrical imaging surveys. Exploration Geophysics, 34(3), 182-187.

Nehaba, M. S., Thabit, J. M., \& Mohammed, A. J., 2019. Using of Ground Penetrating Radar (GPR) for investigate the subsurface archaeological features of Babylon, the Ancient City (Mounts zoona). Iraqi Journal of Science, 60(1), 103-114.

Thabit, J.M., Al-Hameedawie, M.M., 2014. Delineation of groundwater aquifers using VES and 2D imaging techniques in north Badra area, Eastern Iraq. Iraqi Journal of Science, 55 (1), 174-183. 